CHEMISTRY AT THE BRITISH ASSOCIATION. THE papers contributed to Section $B$ at the meetings in South Africa were naturally more limited in number and in range of subject than is usual at ordinary meetings of the association, the majority of the communications having reference either to the chemical aspects of agriculture or to subjects connected with the gold extracting industry. On the other hand, a very active part in the work of the section was taken by the South African chemists, and, almost without exception, the reading of a paper was followed by an animated and interesting discussion.

At Cape Town, the first day of meeting was set aside for the discussion of agricultural and biochemical questions. As it had been arranged that the presidential address should be delivered at Johannesburg, its place was taken by Mr. A. D. Hall's report on recent developments in agricultural science, in which many subjects of special interest in South Africa were discussed. Dealing with the fixation of atmospheric nitrogen through the agency of bacteria, the author pointed out that a sharp distinction must be drawn between the use of pure cultures on old cultivated lands and in new countries, where leguminous crops are often being grown for the first time, and that the behaviour of the lucerne plant under bacterial infection in South African soils is worthy of careful investigation in view of its economic importance in all semi-arid countries. He directed attention to the need of a systematic series of soil analyses, with the ultimate object of making soil maps that shall be of service to the agriculturist, and indicated how much still remains unknown regarding the nutrition of plants and how great is the importance of research in the particular functions of the various constituents of the crop, as it is only through such knowledge that the quality of crops may possibly be influenced in desired directions. A brief discussion of the subjects of acclimatisation and cross-breeding brought to a close an address which aroused very great interest. Dr. Horace T. Brown then gave an account of his researches on the assimilatory processes of plants, in the course of which he described his method by which the assimilative power of leaves was measured for the first time under natural conditions. The quantity of carbon dioxide abstracted from the air by leaves of measured area was estimated in a special absorption apparatus devised for the purpose, and thus it was possible to deduce the amount of carbohydrate formed. The total solar radiation falling on the leaf was measured, and the proportion of the radiant energy of sunlight absorbed and transmitted by the leaf was also arrived at. The author's investigations showed that the rate of growth is not entirely dependent upon the amount of sunshine, but also on secondary causes. The business was brought to a close by a short paper by Dr. E. F. Armstrong on the role of enzymes in plant economy, in which the author directed attention to the fundamental similarity between the action of acids and that of enzymes, the distinction between them arising from the fact that enzymes act selectively in consequence of their power of associating themselves with the hydrolyte. The condition of the carbohydrate in solution is of primary importance, but this condition may to some extent be determined by the enzyme.

At the second day's meeting, Prof. H. B. Dixon gave a historical sketch of researches made on the propagation of explosions in gases, and discussed Berthelot's theory and his own "sound wave" theory on the mode of propagation. With the aid of the lantern he showed how he had followed photographically the flame from its initiation until the setting up of the detonation, and demonstrated the influence of the position of the spark and of the length of the column of exploding gases. $\mathrm{He}$ also described experiments now in progress on the specific heats of gases at high temperatures, and explained how the velocity of sound in a heated gas may be determined. In a second paper Prof. Dixon described the method he has devised for determining the atomic weight of chlorine by the direct burning of a known weight of hydrogen in a known weight of chlorine, the hydrogen, prepared by the electrolysis of barium hydroxide, being occluded in palladium, and the chlorine, prepared by the electrolysis of fused silver chloride, being weighed in the liquid state. The atomic weight obtained is higher than that of Stas, but in close agreement with the recent results of Richards. Messrs. G. T. and H. W. Beilby gave an account of their experiments on the influence of phase changes on the tenacity of ductile metals at the ordinary temperature and at the boiling point of liquid air. They showed that when a wire of ductile metal is stretched to four or five times its original length by drawing it through the holes of a wire plate all the ordinary traces of crystalline structure disappear, but the wire still consists of minute granules of the crystalline phase embedded in a matrix of the amorphous phase. By lowering the temperature of drawing, the mixture approaches more nearly to the homogeneous amorphous state. Observations were made at $15^{\circ}$ and at $-180^{\circ}$ on wires of copper, silver, and gold, which had been as completely as possible converted into the amorphous phase by wire drawing at the ordinary temperature, and in every case the tenacity observed was higher than any recorded by previous investigators for equally pure metals. The wires broken at the ordinary temperature showed no general stretching, but at the boiling point of liquid air all the wires stretched about 12 per cent. Dr. A. Midlay recorded his determinations of the viscosities of liquid mixtures at the temperature of their boiling points, which were made in the expectation that viscosity curves would be obtained similar in form to the boiling-point curves. In the case of benzene and methyl alcohol, the viscosities of which at the respective boiling points are nearly the same, the expectation appears to be realised, but where the viscosities of the pure liquids at their boiling points are not the same certain complications are met with.

The third day of meeting at Cape Town was set apart for communications from local chemists. Prof. P. D. Hahn gave an account of the remarkable thermal chalybeate spring at Caledon, in Cape Colony. With the aid of a tabular statement of the purity ratio of the most famous chalybeate springs, he showed that the Caledon water holds with the water of Spa the first place, but he pointed out that while the waters of most chalybeate springs are very low in temperature, the Caledon spring is unique in so far that the temperature of the water at the eye of the spring is $49^{\circ}$ C. Mr. C. F. Juritz stated that for various reasons very scanty attention has hitherto been paid to purely scientific chemical research in Cape Colony, and gave an interesting account of several investigations made in the Government laboratory under his direction. A chemical survey of the soils of the colony (at present suspended for want of funds) has resulted in the examination of an area of 27,000 square miles, on an average one sample being taken for every 60 square miles. A number of the fodder plants of the Karroo have been examined as regards their nutritive value, estimations of tannin in the barks of various trees have been made, poisonous principles have been extracted from some indigenous plants, and an alkaloid resembling quinine therapeutically, but differing from it chemically, has been extracted from the umjela or quinine tree, which abounds in the Transkei. Clays have been found in various parts of the colony some of which compare favourably in chemical composition with the best fire clays, and mineral pitch has been observed in certain localities. Dr. H. Tietz, in a paper on the character of Cape wines, explained that at the Cape grapes always become perfectly ripe, and thus contain more sugar and less acid than the grapes of the wine-producing countries of Europe. Notwithstanding this, a standing reproach against Cape wines is based on the contention that they contain more acid than European wines. The author investigated this matter on some 300 samples of different Cape wines, and found that the allegation cannot be upheld.

At Johannesburg the proceedings of the section were inaugurated by the delivery of the address of the president, which was of quite exceptional interest. It was followed by a paper by Mr. H. F. Julian, in which an investigation of the part played by oxygen in the dissolution of gold by cyanide solutions was described. The author arrived at the conclusion that free oxygen plays no primary part in the reaction, any assistance given being of a secondary nature, and that, as a matter of fact, it exerts a retarding influence. According to his experiments, while the balance indicates that free oxygen is of material assistNo. 1878 , voL. 72$]$ 
ance, the galvanometer points to its presence hindering the dissolution of the gold; the cause of the disagreement between the instruments he attributes to the formation of local voltaic circuits. Mr. H. A. White gave an account of a series of experiments which showed that thiocyanates in presence of such oxidising agents as ferric salts attack gold with considerable ease, and that thiosulphates exert a similar but less powerful influence. These salts are present in ordinary working cyanide solutions, and the presence of gold in mine reservoirs and in the soil under residue dumps is probably connected with their occurrence. Experiments adduced by the author indicate that in well exposed dumps thiocyanates alone are of significance in respect to the observed solution of gold. A process of residue treatment, based on these facts, is resulting in the profitable extraction of a large proportion of the gold in certain of the residue dumps on the Rand.

At the second day's meeting. Dr. J. Moir discussed the law governing the solubility of zinc hydroxide in alkalis, and as the result of a quantitative research stated the conclusion that the phenomenon is essentially an equilibrium between alkali and zincic acid, which may be reached from both sides, and which depends solely on the concentration of the free alkali. It was also shown that no definite chemical compounds exist in the solution. Mr. G. W. Williams read a paper on the functions of the metallurgical laboratory, dealing with the uses of the laboratory for the testing of supplies and for purposes of research, and with the personnel and equipment of a suitable laboratory. He emphasised the necessity for a highly trained staff, and pointed out defects in the training given in the great English universities. In a valuable contribution, Mr. S. H. Pearce stated and discussed various economic problems in metallurgy on the Rand. Each stage of the whole process of gold extraction was considered from the economic as well as from the scientific standpoint, and the results of the practical experience of years were sum marised in a very clear and judicial manner. Much technical information, of value to all interested in gold extraction, was given in this paper. Mr. R. L. Cousen gave an account of the experiments which led him to conclude that a radio-active substance is present in a certain ore discovered in the Transvaal. If a further examination of the material confirms his belief that the radio-activity of the ore is due to the presence of radium, the result will be of interest in view of the fact that uranium is not present in the ore.

The third day of the meeting was devoted to agricultural chemistry. The proceedings were opened by Mr. A. D. Hall, who discussed in greater detail some of the problems touched on in his address at Cape Town. In a paper on Pretoria rain, Mr. H. Ingle stated that the rain falling at Pretoria for twelve months from February, 1904, was collected, and its content of nitrogen, existing as nitrates, nitrites, and ammonia, determined each week. The results showed that the quantity of combined nitrogen brought down in the rain at Pretoria is considerably greater than the average amounts in Europe, amounting in twelve months to $7.07 \mathrm{lb}$. of nitrogen per acre as compared with the average of $3.84 \mathrm{lb}$. per acre at Rothamsted. In a second paper $\mathrm{Mr}$. Ingle communicated the results of the analyses of some eighty samples of soils collected in various parts of the Transvaal, and drew a comparison between European and Transvaal soils, with special reference to the interconnection of their chemical composition and fertility as indicated by field experience. He showed that to take English standards in judging of fertility from chemical analysis may lead to erroneous conclusions in the case of tropical or subtropical soils, and that if there be a sufficient supply of water a soil of apparently poor quality, from analytical results, may yield luxurious crops under the favouring conditions of growth existent in the Transvaal. Mr. E. H. Croghan, in a paper on the fuel of the midland districts of South Africa, pointed out that a large proportion of potash is found in the excreta of sheep fed in this dry and treeless region, resulting from the composition of the bushes, the foliage of which constitutes the chief food of sheep and cattle. Owing to want of water for irrigation the farmer does not use sheep excreta for manure, but for fuel, and the ashes frequently accumulate near the homestead. Attention was directed to the economic value of these ash heaps, either as a manure or as a source of potassium carbonate. Reports were presented by the committee on wave-length tables of the spectra of the elements, the committee on the study of hydro-aromatic substances, and the committee on the transformation of aromatic nitroamines.

\section{SCIENTIFIC RESEARCH IN MEDICINE.}

THAT great benefits to mankind have followed the discoveries of recent years is obvious to all, especially with regard to the causes and prevention of yellow fever and malaria. Research is a word heard on all sides; it is the enemy of authority, that tyrannous spirit which has hampered progress and retarded the advance of scientific medicine for conturies. Experimental medicine is responsible for the greatest advances which have been made in our knowledge of the cause, prevention, and cure of disease. Most important discoveries have exerted but a slight direct influence at their inception; their full significance has remained hidden for a time. The majority of such discoveries has been made by those engaged in research in the realms of pure science. Pure science is unselfish; its aim is not profit, yet it is the forerunner of that applied science which is more obtrusively the "servant of man." If we study disease, we must do so for the sake of knowledge, the scientific spirit must enter into our work. The "practical man" may not appreciate such ideals, but he is ever ready to use the discoveries of science for his own ends. All are not born with the instincts of research, but there are many in whom they lie dormant, and it should be the function of educational institutions to detect and foster such men and lead them on to do the work for which they are adapted. But too often from mere lack of means such men drift away into other fields of activity. To carry on research successfully a man needs an assured income. Is it possible that those who are able and willing to help human progress can continue to ignore the devotion and self-sacrifice of such men as Lazear, Myers, Dutton, Plehn, and others who have laid down their lives in the study of tropical medicine? Medical research needs endowment, and it is grievous tc see that in this country, where so much is done for charity, so pitiably little is done for the advancement of learning. To teach science as it should be taught in properly equipped and organised institutions is far more expensive in the case of medicine than in that of any other professional school. It does not suffice to build laboratories; they must also be provided with sufficient funds and equipment to enable them to become working entities.

Those who have watched the progress of the London School of Tropical Medicine from its inception have witnessed a struggle upward which is worthy of all praise. This, and the sister institution in Liverpool, are known throughout the world for the excellent work accomplished by the members of the teaching staff and by some of the students they have sent forth. The London School has a great mission to fulfil; it has to train men in the methods they will be called on to employ in many parts of the world, and to give them the latest and the best to take with them on their distant journeys. It is to be hoped that the public will second the noble efforts that have been made to establish a centre for the study of the diseases which affect the inhabitants of the tropical countries of this vast Empire.

\section{The Trend of Recent Investigation.}

A survey of recent work in tropical medicine shows us that investigation is chiefly being directed to the study of protozoal diseases. No advances of fundamental importance have been made with regard to malaria since the classical investigations were published with which the names of Ross and Manson, Grassi, Bignami and Bastianelli will ever remain associated. The earlier work has been confirmed and extended by many investigators. The prevention of malaria by means of mosquito destruction and other measures directed against mosquitoes has been tried in various localities, in some instances with success, 1 From an adniress delivered at the opening of the nineteenth session of Nuttall, F.R.S.

NO. 1878 , VOL. 727 